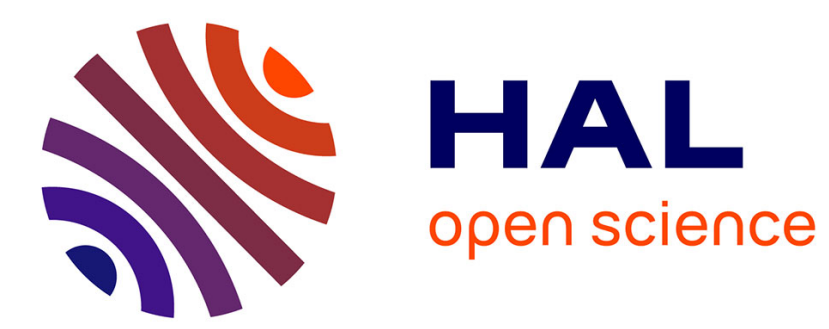

\title{
Rectenna Design for K Band Application
}

Alexandru Takacs, Hervé Aubert, Alexandru Luca, Samuel Charlot, S Fredon, L Despoisse

\section{To cite this version:}

Alexandru Takacs, Hervé Aubert, Alexandru Luca, Samuel Charlot, S Fredon, et al.. Rectenna Design for K Band Application. European Microwave Week (EuMW), Oct 2014, Rome, Italy. hal-02066133

\section{HAL Id: hal-02066133 https://hal.laas.fr/hal-02066133}

Submitted on 13 Mar 2019

HAL is a multi-disciplinary open access archive for the deposit and dissemination of scientific research documents, whether they are published or not. The documents may come from teaching and research institutions in France or abroad, or from public or private research centers.
L'archive ouverte pluridisciplinaire HAL, est destinée au dépôt et à la diffusion de documents scientifiques de niveau recherche, publiés ou non, émanant des établissements d'enseignement et de recherche français ou étrangers, des laboratoires publics ou privés. 


\title{
Rectenna Design for K Band Application
}

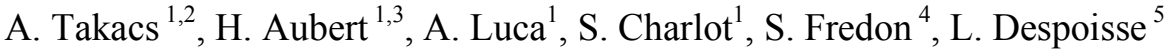 \\ ${ }^{1}$ CNRS, LAAS, 7 avenue du colonel Roche, F-31400, Toulouse, France \\ ${ }^{2}$ Univ de Toulouse, UPS, LAAS, F-31400, Toulouse, France \\ ${ }^{3}$ Univ de Toulouse, INP, LAAS, F-31400, Toulouse, France \\ ${ }^{4}$ CNES (French Space Agency), Toulouse, France \\ ${ }^{5}$ Thales Alenia Space, Cannes, France
}

\begin{abstract}
An ultra-compact $\left(2.5 \mathrm{~cm}^{2}\right)$ rectenna design based on an innovative topology using a coplanar stripline connected to a crossed dipoles antenna array is reported here. Experimental results in the K-band show that a DC power up to $0.9 \mathrm{~mW}$ can be harvested on a $0.3 \mathrm{k} \Omega$ load by using the proposed compact rectenna for incident power density of $1413 \mu \mathrm{W} / \mathrm{cm}^{2}$. The targeted application for this rectenna is to power autonomous wireless sensors for satellite health monitoring.
\end{abstract}

\section{Keywords - Rectenna, energy harvesting, satellite application}

\section{INTRODUCTION}

Recently, the topics of energy harvesting for satellite health monitoring was explored [1]-[3]. The idea consists of harvesting the spill-over loss of microwave antenna (operating in $\mathrm{C}, \mathrm{X}, \mathrm{Ku}, \mathrm{K}$ or $\mathrm{Ka}$ bands) of broadcasting satellites by using appropriate rectenna designs. This harvested DC power available over the satellite lifetime can be used to power autonomous wireless sensors for satellite health monitoring. Rectenna topologies working on frequencies beyond $10 \mathrm{GHz}$ were addressed for microwave power transmission [4]-[6], 24 GHz ISM band applications [7]-[9] or more recently satellite hearth monitoring [1]-[3]. This paper addresses an innovative rectenna topology for $\mathrm{K}$ band application. The design methodology, simulation and experimental results are presented in order to underline the performances of the proposed design.

\section{RECTENNA DESIGN}

\section{A. Topology}

The proposed topology is based on the use of a high gain planar antenna directly connected with a high frequency rectifier using (only) one Schottky diode. Fig. 1 shows the top view of the rectenna while its bottom view is represented in Fig. 2. The antenna consists of an array of two planar crossed dipoles. The rectifier consists of (i) a Schottky diode mounted on the top side of the planar circuit board (PCB) and (ii) a lumped filtering capacitor of $1.5 \mathrm{pF}$ and a load (see Fig.2). Thus, the low-pass filtering function is achieved by the coplanar strip supported structure mounted on the bottom side of the rectenna. The connection between the diode and the lowpass filter is performed by using two via holes. The matching between antenna and rectifier input impedances is achieved by properly controlling the mounting position of the Schottky diode.

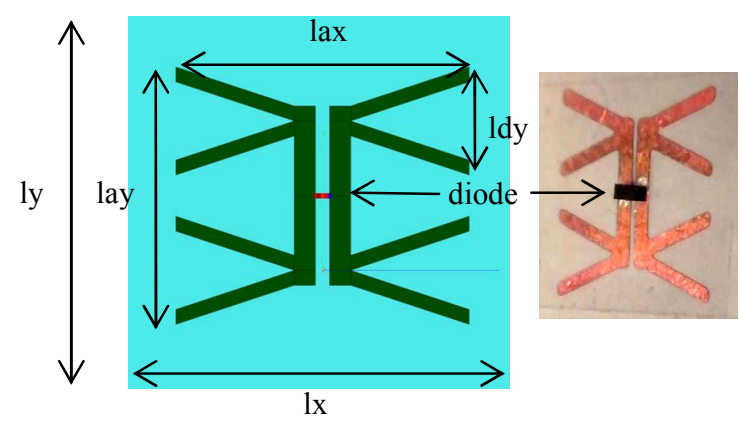

Fig. 1. Top view (left, not to scale) of the simulation model (FEKO) and a photo (top side) of the manufactured rectenna (right).

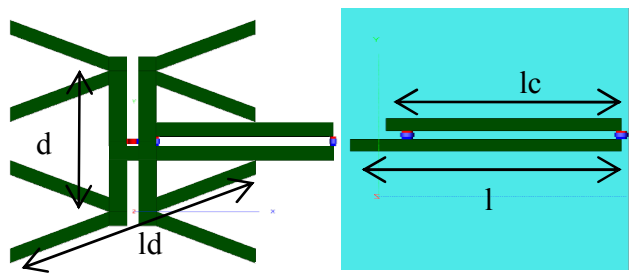

Fig. 2. Top view (left, not to scale) of the simulation model (PCB substrate is not represented) and bottom view (right, not to scale) of the rectenna.

Rectennas using coplanar stripline structures are reported in [2],[3] and [5] while microstrip supported topologies are reported in [2]-[3], [6]-[8]. A substrate integrated waveguide (SIW) rectenna is reported in [9].

\section{B. Antenna design}

The antenna located on the top side can be viewed as an array composed by 4 printed half-wavelength dipoles. This antenna is called here the crossed dipoles array antenna (CDAA). The maximum theoretical gain (Gmax in $\mathrm{dBi}$ ) of such an array antenna can be computed using the following formula:

$$
G \max =10 \cdot \log (4)+G d=6+2.15=8.15 \mathrm{dBi}
$$

where $G d=2.15 \mathrm{dBi}$ is the gain of a lossless half-wavelength dipole. This gain is $3 \mathrm{~dB}$ higher when a metallic reflector is properly positioned below the antenna surface. Thus the expected maximum gain is $11.15 \mathrm{dBi}$. The main geometrical parameters for optimizing CDAA performances are: the length of the crossed dipole arms (ld), the angle between crossed dipoles $(\alpha)$, the array step (d), the strip width (w) and the gap between the strips of the coplanar stripline $(\mathrm{g})$. The length of 
the crossed dipole arms (ld) and the array step must be close to the half-wavelength. The optimization procedure for CDAA is described in the next section. A standard 3D Cartesian coordinate system with the vertical $\mathrm{Oz}$ axis perpendicular to the rectenna/CDAA surface is chosen here. The diode was replaced by a voltage port while the capacitance $(1.5 \mathrm{pF})$ and the load (e.g. $300 \Omega$ ) were modeled as port loads. By adopting this simulation model the impact on antenna performances of the overall rectifier layout (except the non-linear behavior of the diode) is estimated. Fig. 3 shows the simulated gain (by using FEKO software) in two vertical planes (xOz-plane: phi $=0^{\circ}$ and yOz-plane: phi $=90^{\circ}$ ) at $17.7 \mathrm{GHz}$. The half-power beamwidth is $60^{\circ}$. The inset of Fig. 3 shows the simulated 3D radiation pattern of the optimized CDAA at $17.7 \mathrm{GHz}$.

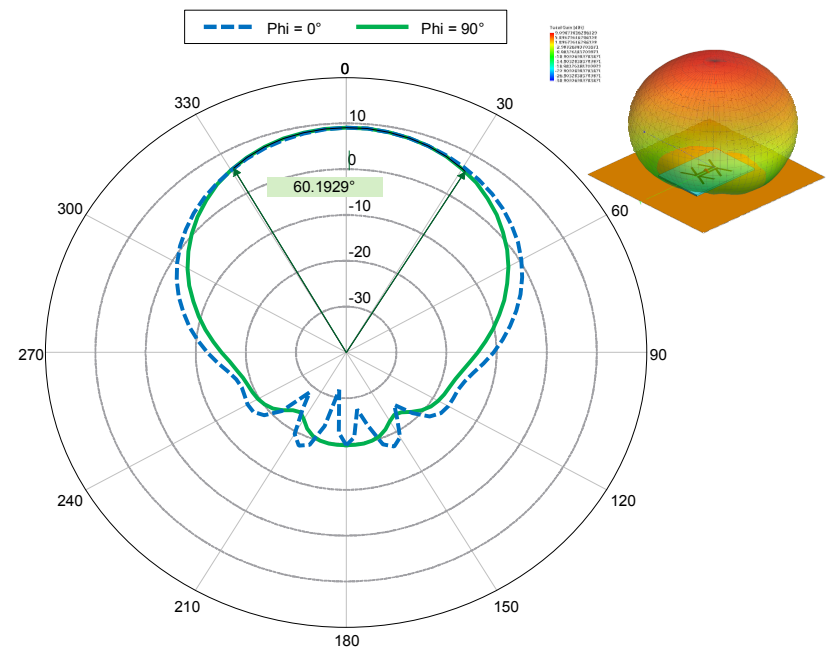

Fig. 3. Simulated (FEKO) gain of the CDAA (xoz-plane: phi $=0^{\circ}$ and yozplane: phi $=90^{\circ}$ ) at the frequency $\mathrm{f}=17.7 \mathrm{GHz}$.

The gain in the direction of Oz-axis as a function of the frequency is depicted in Fig. 4. This gain is higher than 8.5 $\mathrm{dBi}$ in the analyzed frequency band $(17 \mathrm{GHz}-24 \mathrm{GHz})$ and reaches its maximum $(11 \mathrm{dBi})$ at $22.3 \mathrm{GHz}$.

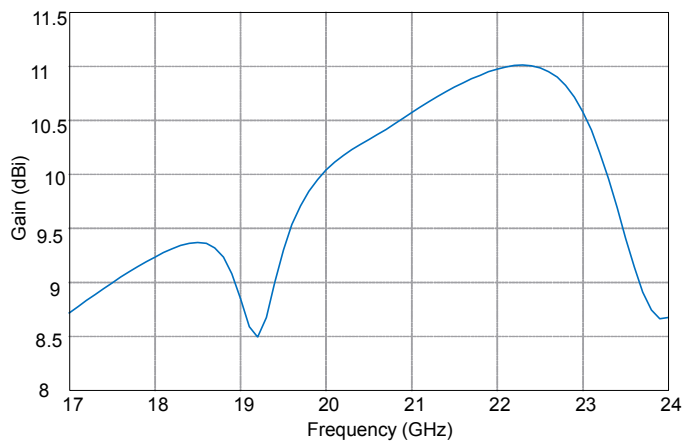

Fig. 4. Simulated gain (FEKO) along Oz-axis versus frequency.

The simulated input impedance viewed by the diode port of the CDAA (rectenna) is depicted in the Fig. 5. This impedance (Zin a) should be the conjugate of the input impedance of the rectifier (Zin_r) in order to achieve the maximum power transfer between CDAA and the rectifier.

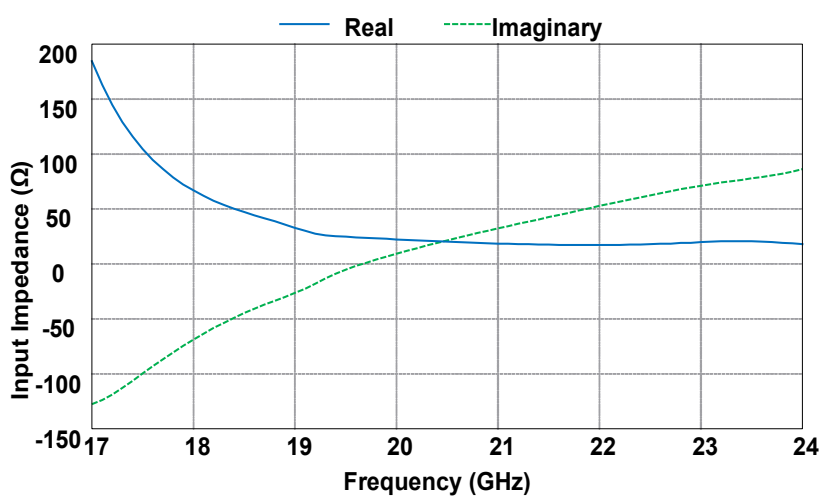

Fig. 5. Simulated input impedance (FEKO) of the CDAA (rectenna) structure viewed by diode port.

\section{Design Methodology}

A low-cost silicon Schottky diode (SMS201 from Aeroflex Metelics) in a molded plastic (DFN) package was adopted for this design. This diode is designed for a broadband zero bias detector. It can be used below $26.5 \mathrm{GHz}$ for power detection up to $10 \mathrm{dBm}$. Most of previously reported designs below 10 $\mathrm{GHz}$ uses GaAs Schottky diodes with an higher cut-off frequency (e.g. M/A Com MA4E-1317 diode used in [1][2],[6],[8] has a cut-of frequency of $70 \mathrm{GHz}$ while the Metelics MZBD-9161 diode used in [1]-[3] has a cut-off frequency of $110 \mathrm{GHz}$ ). This low-cost silicon diode has also a good thermal behavior and can be mounted using a classical soldering process at high temperature $\left(260^{\circ} \mathrm{C}\right)$ while the above-mentioned GaAs diodes require a more sensitive mounting process at a lower temperature $\left(<150^{\circ} \mathrm{C}\right)$.

The proposed design methodology combines full-wave electromagnetic simulation (for CDAA) and non-linear circuit simulation (for rectifier part). The main goal is to simultaneously achieve a high gain for the CDAA with an acceptable matching in a large bandwidth between CDAA and the rectifier for various load impedance and incident RF power. This was performed for maximizing the overall conversion efficiency of the rectenna. The design procedure consists of the following steps:

(i) the CDAA was first designed, simulated and optimized using FEKO software for operation in the desired frequency band. The diode was replaced by a voltage port while the capacitance $(1.5 \mathrm{pF})$ and the load (e.g. $300 \Omega$ ) were modeled as port loads. The antenna radiation pattern and the distribution of the electric currents on the metallic strips were simulated in order to insure the proper radiation mechanism and to maximize the gain in the Oz-axis direction (that is, in the direction perpendicular to the rectenna surface);

(ii) the input impedance (Zin_a) as well as the gain along the Oz-axis (theta $=0^{\circ}$; phi $=0^{\circ}$ ) of the CDAA (simulation model shown in Fig. 1) was computed in the targeted frequency band as a function of the diode/capacitance mounting position; 
(iii) non-linear (harmonic balance) simulation was performed by using the AWR software for the rectifier part of the rectenna. The coplanar stripline sections supporting the rectifier were modeled as a sub-circuit at the electromagnetic level because of the lack of an appropriate transmission line model in AWR. A generic non-physical diode model available in AWR was customized with the SMS201 diode parameters [10]. The input impedance (Zin_r) of the rectifier was determined as a function of the diode/capacitance mounting position;

(iv) the position the capacitance was adjusted to ensure the matching condition, that is $\mathrm{Zin} a=\mathrm{Zin} \mathrm{r}^{*}$ where the asterisk denotes the complex conjugated.

\section{RECTENNA: EXPERIMENTAL RESULTS}

The rectenna was fabricated on Rogers 6002 substrate (relative permittivity: 2.94, loss tangent: 0.0012, thickness: $508 \mu \mathrm{m})$. The layout was accommodated with the manufacturing tolerances available in a university unit equipped for general (low frequency) PCB manufacturing. A metallic plane (size: $\approx 4 \mathrm{~cm} \mathrm{x} 4 \mathrm{~cm}$ ) was positioned at $1.2 \mathrm{~mm}$ below the rectenna. A $1.2 \mathrm{~mm}$ thick Rohacell HF51 [13] (dielectric constant in the range of 1.08) layer was used as spacer between rectenna and its reflector. The main dimensions of the manufactured rectenna (see Fig. 1 and Fig. 2) are: $1 x=1.4 \mathrm{~mm}, l y=1.8 \mathrm{~mm}, \quad l a y=10 \mathrm{~mm}, \quad l a x=8.3 \mathrm{~mm}$, $\mathrm{lad}=4.3 \mathrm{~mm}, \mathrm{l}=7 \mathrm{~mm}$ and $\mathrm{lc}=6 \mathrm{~mm}$.

\section{A. Experimental Setup}

An experimental setup (shown in Fig. 6) was used in order to recreate the electromagnetic environment existing on antenna panels of the broadcasting satellites. A microwave signal generated from an Anritsu MG3694B generator was injected at the input of a horn antenna (VT220HA20-SK from Vector Telecom) which illuminated the rectenna under test with a linear polarized E-field.

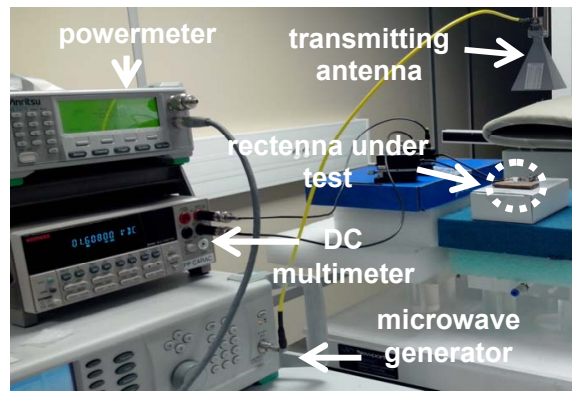

Fig. 6. Experimental setup used for characterizing the performances of manufactured rectennas .

The power density $\left(\mu \mathrm{W} / \mathrm{cm}^{2}\right)$ can be computed as a function of E-field effective value $\mathrm{E}(\mathrm{V} / \mathrm{m})$ on the antenna surface or as a function of the RF power $\mathrm{P}_{t}$ delivered to the transmitting horn antenna of gain $G_{t}$ and positioned at the distance $d$ from the rectenna under test, as follows:

$$
S=\frac{E^{2}}{120 \cdot \pi} \cdot 100=\frac{30 \cdot P_{t} \cdot G_{t}}{d^{2} \cdot 120 \cdot \pi} \cdot 100
$$

An automatic acquisition routine was implemented in Labview software from National Instruments to speed-up the acquisition process. The harvested DC voltage was measured with the microwave source OFF (DC noise: V_off) and with microwave source ON (DC voltage: V_on). The DC voltage of interest (V_DC) was then derived from the difference V_DC $=$ V_on - V_off. The DC power can be computed from the measured DC voltage as long as the load is known. The measured loss due to the coaxial cable and connectors between antenna and the signal generator was in the range of $2.5 \mathrm{~dB}$ in the operating frequency band.

\section{B. Simulation and Experimental Results}

The frequency of $17.7 \mathrm{GHz}$ was targeted by our design because available cartographic maps (for the expected E-field values on the $\mathrm{K}$ band antenna panels) indicated that an incident E-field up to $127 \mathrm{~V} / \mathrm{m}$ may illuminate few regions of these panels [2]. Nevertheless the adopted 'non-resonant' matching technique (between CDAA and the rectifier) can provide a wideband behavior to the rectenna. The simulated non-linear input impedance (obtained by using AWR software and harmonic balance technique) of the rectifier is represented in the Fig. 7. The estimated RF power of the input at $f=17.7$ $\mathrm{GHz}$ of rectifier by using Friis free-space formula [12] (with injected power into the transmitting antenna: $\mathrm{P}_{\mathrm{t}}=23.5 \mathrm{dBm}$, measured gain of the transmitting horn antenna: $\mathrm{G}_{\mathrm{t}} \approx 18 \mathrm{dBi}$, receiving CDAA simulated gain antenna $\mathrm{G}_{\mathrm{r}} \approx 9 \mathrm{dBi}$, distance between the input port of the transmitting and the receiving antenna $\mathrm{d}=25 \mathrm{~cm}$ ) is in the range of $5 \mathrm{dBm}$. The simulated (AWR) nonlinear input impedance of the rectifier derived from Fig. 7 is $Z$ in_r $\approx(76+42 * j) \Omega$ while the simulated (FEKO) input impedance of the CDAA (Fig. 5) is Zin $\mathrm{a} \approx(86-87 * \mathrm{j}) \Omega$.

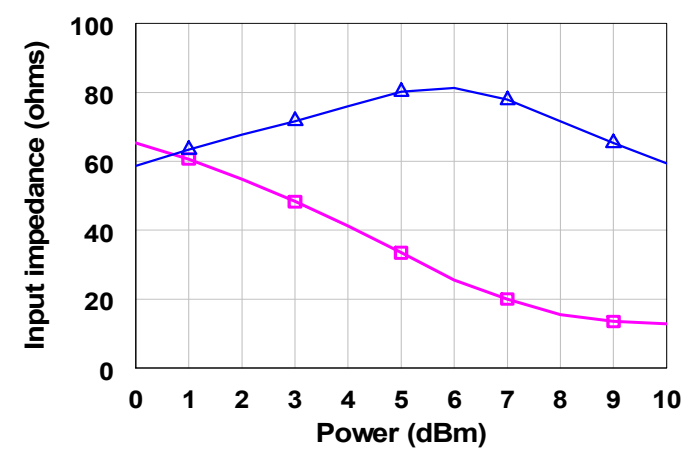

Fig. 7. Simulated (AWR) nonlinear input impedance (traingle marker: real part; square marker: imaginary part) of the rectifier as function of the RF power at the rectifier input (frequency $\mathrm{f}=17.7 \mathrm{GHz}$ ).

The measured DC power at the input of an (optimal) resistive load of $300 \Omega$ by using the setup described in the section II. A (Fig. 6) is shown in the Fig. 8. These measurement results were obtained at $\mathrm{f}=17.7 \mathrm{GHz}$. The delivered power of the Anritsu MG3694B signal generator was $\mathrm{P}=25 \mathrm{dBm}$ while the injected power on the coaxial input port of the transmitting horn antenna was in the range of 22.5 $\mathrm{dBm}$. 


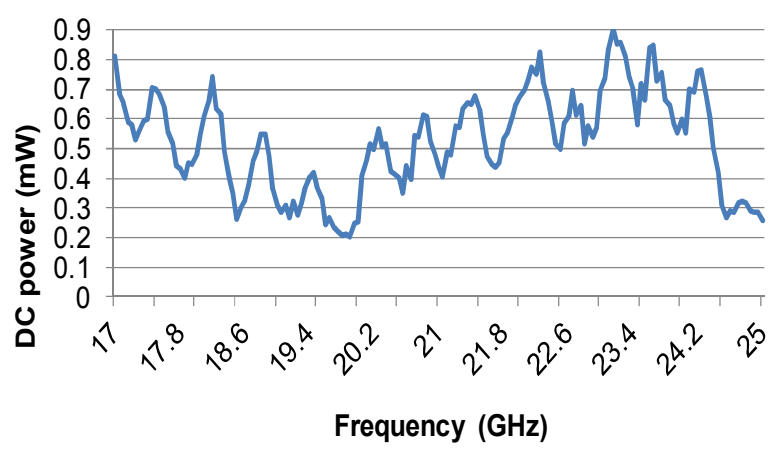

Fig. 8. Simulated (AWR) nonlinear input impedance (traingle marker: real part; square marker: imaginary part) of the rectifier as function of the RF power at the rectifier input (frequency $\mathrm{f}=17.7 \mathrm{GHz}$ ).

Due to the inherent limitations of the adopted design methodology and simulation models the obtained DC power at 17.7 is $0.52 \mathrm{~mW}$. A maximum DC power of $0.9 \mathrm{~mW}$ on a $0.3 \mathrm{k} \Omega$ load was obtained at $\mathrm{f}=23.15 \mathrm{GHz}$. At this frequency the gain of CDAA along the Oz-axis reaches a maximum value of $11 \mathrm{dBi}$ while the simulated gain (along the Oz-axis) is $9 \mathrm{dBi}$ at 17.7 GHz. The efficiency $\eta$ (in \%) of a rectenna can be computed by using the following worst-case definition [13]:

$$
\eta=\frac{P_{D C}}{S \cdot A_{G}} \cdot 100
$$

where $\mathrm{P}_{\mathrm{DC}}$ is the harvested $\mathrm{DC}$ power, $\mathrm{S}$ is the incident electromagnetic power density and $\mathrm{A}_{\mathrm{G}}\left(\right.$ in $\mathrm{cm}^{2}$ ) denotes the area of the radiating surface. Here $\mathrm{P}_{\mathrm{t}} \approx 22.5 \mathrm{dBm}, \mathrm{G} \approx 18 \mathrm{dBi}$ and $\mathrm{d}=25 \mathrm{~cm}$. Thus $\mathrm{E} \approx 73 \mathrm{~V} / \mathrm{m}$ and $\mathrm{S} \sim 1413 \mu \mathrm{W} / \mathrm{cm}^{2}$. By taken into account the overall area of the rectenna $\mathrm{A}_{\mathrm{G}} \approx 2.5 \mathrm{~cm}^{2}$ a worst-case conversion efficiency around of $15 \%$ at $17.7 \mathrm{GHz}$ (harvested DC power: $0.9 \mathrm{~mW}$ ) and $25 \%$ at $23.15 \mathrm{GHz}$ (harvested DC power: $0.9 \mathrm{~mW}$ ) were obtained.

The proposed design methodology suffers from several limitations: (i) the impact of the nonlinear behavior of the diode on antenna is neglected during CDAA design as explained in section II.B; (ii) the impact on rectenna performances of the diode package and of the two via holes used to connect the diode (mounted on the top side of the rectenna) with the low-pass filtering section of the rectifier (located on the bottom side) is not taken into account in the AWR model; (iii) the simulation model adopted for the diode could be improved because key parameters of the diode (series resistance, ideality factor, etc.) are not provided in the datasheet [10]. Also, the PCB was fabricated in a university unit equipped for standard (low frequency) PCB low-cost manufacturing. The capacitance mounting position is critical and the exact mounting position is not well controlled by the adopted manual assembly process (tolerances in the range of $0.5 \mathrm{~mm}$ ). Works are under run in order to overcome these limitations and to improve the global rectenna efficiency.

\section{CONCLUSION}

An innovative rectenna topology and the adopted design methodology for $\mathrm{K}$ band application were presented. With only one low-cost silicon Schottky diode and using this ultracompact rectenna $\left(2.5 \mathrm{~cm}^{2} / 1.5\right.$ square wavelengths at $\left.23 \mathrm{GHz}\right)$ a DC power up to $0.9 \mathrm{~mW}$ can be harvested for an incident $\mathrm{E}$ field close to $73 \mathrm{~V} / \mathrm{m}$ in the $\mathrm{K}$ band.

\section{ACKNOWLEDGMENT}

This work was supported by CNES French Space Agency within the framework of R\&T $n^{\circ} 115052$ contracts. The electronic laboratory of University of Toulouse (Paul Sabatier) is acknowledged for PCB manufacturing. The authors acknowledge the support of the European Commission and of the National Funding Agency from France (Region MidiPyrénées) through the MNT-ERA.NET project MEMIS (MEMS based Millimeter wave Imaging System) for developing the simulation models of the Schottky diodes used in the design of our rectenna.

\section{REFERENCES}

[1] A. Takacs, H. Aubert, L. Despoisse, S. Fredon, 'Microwave energy harvesting for satellite applications', IET Electronics Letters, Issue 11, Vol. 49, pp. 722-723, 23 May 2013.

[2] A. Takacs, H. Aubert, S. Fredon, L. Despoisse, H. Blondeaux, "Microwave Power Harvesting for Satellite Health Monitoring", accepted to IEEE Trans. Microw. Theory Techn., to be published in the Special Issue on Wireless Power Transfer (March 2014)

[3] A. Takacs, H. Aubert, S. Fredon, L. Despoisse, "Compact Rectenna for Space Application," accepted to IMS'2014, Tampa, USA, juin 2014.

[4] B. Strassner, K. Chang, "Microwave Power Transmission: Historical Milestones and system Components", Proceedings of the IEEE, Vol. 101, No. 6, pp.1379 -1395, June 2013.

[5] T.-W. Yoo and K. Chang, "Theoretical and experimental development of 10 and $35 \mathrm{GHz}$ rectennas," IEEE Trans. Microw. Theory Techn., vol.40, no. 6, pp. 1259-1266, Jun. 1992.

[6] Y.-J. Ren, M.-Y. Li, K. Chang, "35 GHz rectifying antenna for wireless power transmission," IET Electronics Letters, vol.43, no.11, pp.602-603, May 242007.

[7] N. Shinohara, K. Nishikawa, T. Seki, K.Hiraga, "Development of 24 $\mathrm{GHz}$ rectennas for Fixed Wireless Access," 2011 URSI General Assembly and Scientific Symp., pp.1-4, 13-20 Aug. 2011.

[8] S. Ladan, and K. Wu, "High Efficiency Low-Power Microwave Rectifier for Wireless Energy Harvesting”, in Proc. IMS'2013, 2013.

[9] A. Collado, A. Georgiadis, "24 GHz Substrate Integrated Waveguide (SIW) Rectenna for Energy Harvesting and Wireless Power Transmission, in Proc. of IMS'2013, 2013.

[10] http://www.aeroflex.com/AMS/Metelics/pdfiles/SMS201.pdf

[11] http://www.rohacell.com/sites/dc/Downloadcenter/Evonik/Product/ROH ACELL/productinformation/ROHACELL\%20Dielectric\%20Properties.pdf

[12] C. A. Balanis, "Antenna Theory: Analysis and Design, 3rd Edition," Willey edition, 2005.

[13] Z. Popovic; E.A. Falkenstein, D. Costinett, R. Zane, "Low-Power FarField Wireless Powering for Wireless Sensors", Proceedings of the IEEE, Vol. 101, No. 6, pp.1397 -1407, June 2013. 